\title{
Lutetium incorporation in magmas at depth: changes in melt local environment and the influence on partitioning behaviour
}

Charlotte J. L. de Grouchy ${ }^{1 *}$, Chrystèle Sanloup ${ }^{2}$, Benjamin Cochain ${ }^{2}$, James W. E. Drewitt $^{3}$, Yoshio Kono ${ }^{4}$, Céline Crépisson ${ }^{2}$

${ }^{1}$ Centre for Science at Extreme Conditions and School of Physics and Astronomy, University of Edinburgh, EH9 3FD, UK. *Corresponding author (c.degrouchy@ed.ac.uk).

${ }^{2}$ Sorbonne Universités, UPMC Univ Paris 06, CNRS, Institut des Sciences de la Terre de Paris (ISTeP), 75005 Paris, France

${ }^{3}$ School of Earth Sciences, University of Bristol, Wills Memorial Building, Queens Road, Bristol, BS8 1RJ, UK.

${ }^{4}$ HPCAT, Geophysical Laboratory, Carnegie Institution of Washington, USA

\section{Abstract}

The structure of two Lu doped (4000 ppm) model end member silicate liquids, a highly polymerised haplogranite (Si-Al-Na-K-O) and a less polymerised anorthite-diopside (SiAl-Mg-Ca-O), have been studied up to $8 \mathrm{GPa}$ using in situ x-ray diffraction techniques. The results are the first to identify trace rare Earth element incorporation in silicate melts at high pressure. At pressures below $5 \mathrm{GPa}$, the bonding environment of Lu-O was found to be dependent on composition with coordination number $C N_{\mathrm{Lu}-\mathrm{O}}=8$ and bond distance $r_{\mathrm{Lu}-\mathrm{O}}=2.36 \AA$ in the haplogranite melt, decreasing to $C N_{\mathrm{Lu}-\mathrm{O}}=6$ and $r_{\mathrm{Lu}-\mathrm{O}}=2.29 \AA$ in the anorthite-diopside melt. This compositional variance in coordination number at low pressure is consistent with observations made for Y-O in glasses at ambient conditions and is coincident with a dramatic increase in the partition coefficients previously observed for rare Earth elements with increasing melt polymerisation. With increasing pressure we find that $C N_{\mathrm{Lu}-\mathrm{O}}$ and $r_{\mathrm{Lu}-\mathrm{O}}$ remain constant in the haplogranite melt. However, an abrupt change in both Lu-O coordination and bond distance is observed at $5 \mathrm{GPa}$ in the anorthite-diopside melt, with $C N_{\mathrm{Lu}-\mathrm{O}}$ increasing from 6 to 8-fold and $r_{\mathrm{Lu}-\mathrm{O}}$ from 2.29 to $2.39 \AA$. This occurs over a similar pressure range where a change in the P-dependence in the reported rare Earth element partition coefficients is observed for garnet-, clinopyroxene-, and olivine-melt systems. This work shows that standard models for predicting trace elements at depth must incorporate the effect of pressure-induced structural transformations in the melt in order to realistically predict partitioning behaviour. 


\section{Introduction}

Trace elements are highly fractionated during planetary differentiation events, because of differential partitioning between minerals, melts and metals at high pressures $(P)$ and temperatures $(T)$. The resulting partition coefficients are used as key indicators of depth, temperature, composition and potential age of melting events since planetary formation (McIntire (1963)). Trace element partitioning behaviour at mantle pressures is of particular interest for dating early crust formation on Earth and the Lu/Hf isotope system is regularly used to constrain early Earth melting processes (Guitreau et al. (2012)). Many studies have shown that variables such as composition, $P, T$ and oxygen fugacity have a control on the mineral/melt partitioning of trace elements (see Wood and Blundy (2013) and references within). Although it has long been recognised that crystal chemistry and composition play a major role in controlling how elements partition (Blundy and Wood, 1994), fewer studies have focused on the influence of the melt structure due to the lack of systematic experimental data (Corgne et al., 2012).

Variations in the melt however do influence partitioning significantly, as first reported by several compositional studies, e.g. olivine/melt Ni partitioning (Hart and Davis, 1978), rare earth elements (REEs) partitioning between granitic and gabbroic melts (Ryerson and Hess, 1978; Schmidt et al., 2006), REE clinopyroxene/melt partitioning (Gaetani, 2004), titanite/melt trace element partitioning (Prowatke and Klemme, 2005), REE forsterite/melt partitioning (Evans et al., 2008). As the polymerisation of the melt was increased, a two orders of magnitude increase in partition coefficient for trivalent rare earth elements such as Lu, Y, La, is observed with high field strength elements (HFSE) such as Hf and Zr unaffected (Prowatke and Klemme, 2005; Schmidt et al., 2006). Prowatke and Klemme (2005) concluded that the polymerisation of the melt reduces the number of non-bridging oxygens available to bond with the trivalent cations, resulting in a preference for REEs to enter less polymerised melt structures. This was confirmed by a molecular dynamic study of $\mathrm{Y}$ in silicate melts (Haigis et al., 2013), that demonstrated the greater affinity of $\mathrm{Y}$ for Ca than for Si or Al in depolymerized melts, due to the weaker nature of the $\mathrm{Ca}-\mathrm{O}$ bond compared to the $\mathrm{Si}(\mathrm{Al})-\mathrm{O}$ bonds, resulting in more non-bridging oxygens being effectively available for Y. If pressure also has a significant effect on the melt structure and influence the compatibility of elements, then our current perception of how these element pairs behave at the conditions of melting may be altered.

To predict partitioning ratios, current models are based on experimental data for 
partition coefficients measured within individual systems and extrapolated for different size and charge of cations. One model that is frequently used to predict partitioning ratios is the 'lattice strain model' (Blundy and Wood, 1994). This incorporates the effect of ionic radius, charge and cation size in a model that links the parabolic relation between the partition coefficient and ionic radius with the size of the ion and Young's modulus or elasticity of the lattice site. No explicit term for the effect of melt structure is included as it is assumed to be negligible and can be summarised within the initial measured partitioning ratio $D_{0}$, which normalises the partition coefficient of a chosen cation with a specific melt composition.

Amongst the few existing studies on REE partitioning with pressure, only the garnet/melt, clinopyroxene/melt and olivine/melt systems have been studied over a $P$ range large enough to cover most terrestrial magmatic processes i.e. up to 5-6 GPa, other studies being restricted to below 3.5 GPa. The garnet/melt studies show a change in the $P$-dependence of mineral/melt partitioning, with an initially large decrease in partition coefficient and a compatibility plateau after $5 \mathrm{GPa}$. (Figure 1). For Hf and $\mathrm{Zr}$ this trend was not observed and they were largely unaffected. This would suggest that at $P>5 \mathrm{GPa}$ partition coefficients between REE and $4+$ cations may become similar. The transition to majorite may be the cause of this change in REEs partitioning behaviour (Draper et al., 2003), however, it does so at the cost of a reduced site elasticity and reduced cation size which is incompatible with mineral physics rules. To solve inconsistencies in apparent site elasticity trends, van Westrenen and Draper (2007) introduced corrections for $T$ including an empirical correction for site elasticity by fitting a larger set of garnet/melt partitioning data. Under increased $T, D^{\text {mineral/melt }}$ is expected to get closer to unity due to the induced thermal disorder on crystal lattice sites. This better parameterisation of the lattice strain model clearly improved its robustness, although site elasticity values outside the 500-600 GPa range still cannot be reproduced. Besides, later datasets showed the strongest $P$-change of $D_{\mathrm{Lu}}^{\text {garnet/melt }}$ between 3 and $8 \mathrm{GPa}$ (Figure 1), where data were collected over a $100 \mathrm{~K}$ T-range only (Suzuki et al., 2012). Datasets collected on larger P-ranges (up to 17 GPa for (Corgne et al., 2012) and 20 GPa for Suzuki et al. (2012) vs up to 10 GPa for van Westrenen and Draper (2007)) point out a worsening of the predictive value of the model at higher pressures. Clinopyroxene/melt partitioning studies at $P$ up to $3.5 \mathrm{GPa}$ have been parameterized by Wood and Blundy (1997) and subsequent papers. The exploration of a larger compositional space at $1.5 \mathrm{GPa}$ demonstrated the dependence of $D_{\mathrm{REE}}^{\mathrm{CPx} / \text { melt }}$ on melt polymerization 
rather than crystal composition (Gaetani, 2004), an effect restrained to compositions closed to the lherzolite solidus. Higher $P$ data collected up to $12 \mathrm{GPa}$ (Suzuki et al., 2012) show an overall similar $P$-trend to the garnet/melt system (Figure 1 ). In the case of olivine/melt data, the REE partition coefficients decrease with increasing silica in the melt at room $P$ (Evans et al., 2008). This is at odds with the main stream of studies showing the opposite behaviour (Hart and Davis, 1978; Ryerson and Hess, 1978; Prowatke and Klemme, 2005; Schmidt et al., 2006), and might be taken with caution as the authors pointed out the poor fit statistics (Evans et al., 2008). Under high $P$, REE partition coefficients between olivine and peridotitic melt for $3+$ cations decrease with increasing pressure between 2-10 GPa (Imai et al., 2012). As for garnet, the apparent site elasticity behaves anomalously with $P$, decreasing by $200 \mathrm{GPa}$ of which the $T$-effect can only explain a maximum of $33 \mathrm{GPa}$. Instead, Imai et al. (2012) proposed that elasticity of the cation site in the melt affects partitioning as changes on the crystal lattice alone would not produce a large enough effect. It is currently challenging to test this hypothesis without a proper understanding of site elasticity in melts. It is nonetheless true that the large compressibility difference between melts and crystals that exists at ambient pressure largely diminishes with pressure (see Sanloup (2016) for a review and references therein) as the melt becomes much harder to compress. Consequently, it is expected that the strain energy resulting from the insertion of REE elements in the melt ceases to be negligible. However, the fine $P$-mesh available for the Gt/melt system implies that the strong change in $P$-dependence of $D_{\mathrm{Lu}}^{\mathrm{Gt} / \mathrm{melt}}$ excludes a purely gradual transformation, an effect that could be artificially smoothed for $\mathrm{CPx} /$ melt, Olivine/melt systems due to the insufficient mapping of the $P$ space. Rather, the observations on garnet/melt, clinopyroxene/melt and olivine/melt systems, taken together, point to a potential change in trace element local environment. As pointed out by Haigis et al. (2013), if melt properties exert some control on element partitioning, their influence is hidden in the adjustable parameters used in current lattice strain models, and as such, cannot be predicted nor explained by the model. In their development of a predictive mineral-melt partitioning model for clinopyroxene, Wood and Blundy (1997) assumed that mineral-like trace element sites are present in silicate melt. However, if the nature of the quasi-crystalline components changes, the energetics of partitioning are such that partitioning should also change (van Westrenen et al., 2000).

Studies on silicate glasses, and more recently liquids, have shown that structural alterations do occur within the liquid with increasing pressure. For example, major 


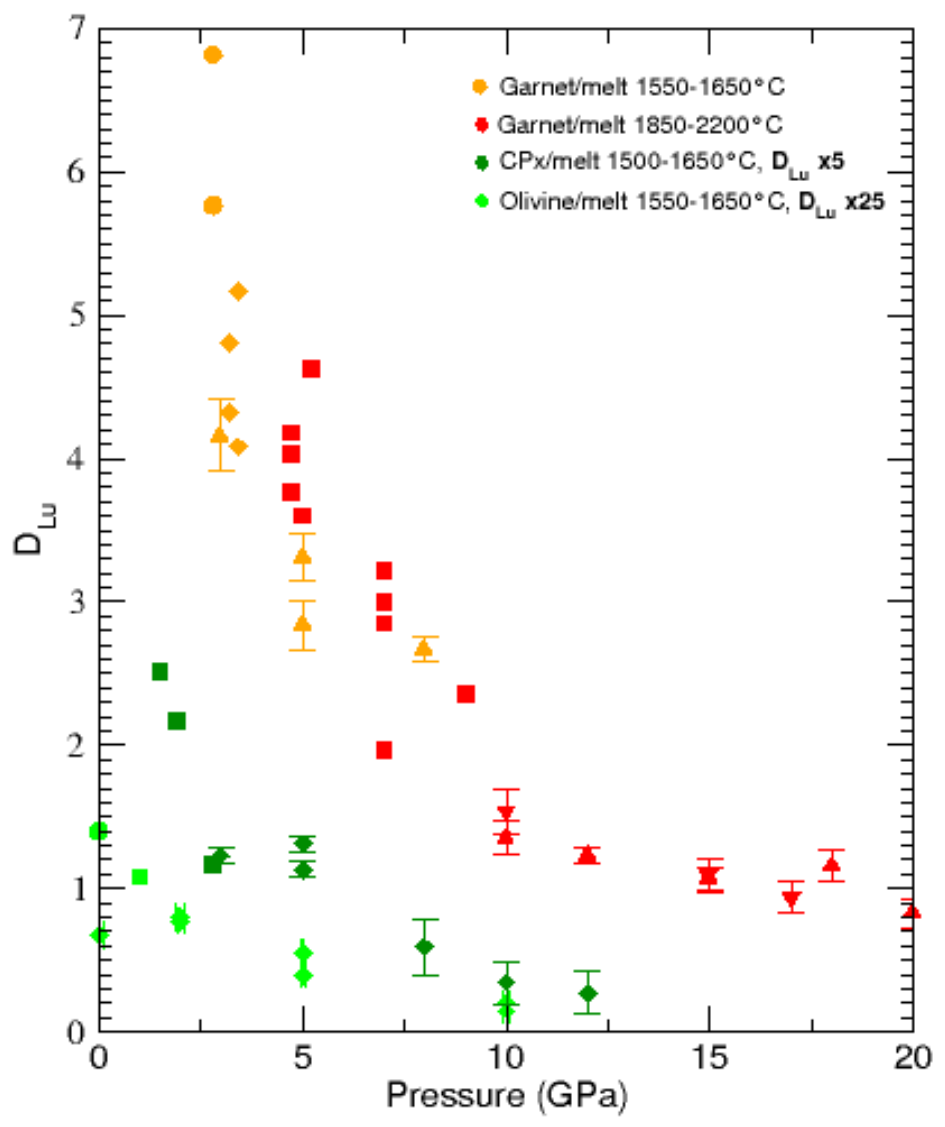

Figure 1: Mineral-melt partition coefficient data $\left(D_{\mathrm{Lu}}^{\mathrm{min} / \mathrm{melt}}\right)$ for Lu with pressure. For the sake of intercomparison, $D_{\mathrm{Lu}}^{\mathrm{CPx} / \text { melt }}$ have been multiplied by 5 , and $D_{\mathrm{Lu}}^{\mathrm{Olivine} / \mathrm{melt}}$ multiplied by 25 . Data presented are from studies where the composition was consistent over all $P$ - $T$ conditions, i.e. basaltic composition for garnet and clinoyroxene studies, and peridotitic composition for olivine studies. Other studies (i.e. van Westrenen et al. (1999)) have varying starting compositions that may mask any $P$ effects; similarly, datasets have been limited to restricted $T$-range for $\mathrm{Gt} /$ melt and $\mathrm{CPx} /$ melt studies, which was not possible for olivine/melt due to the small number of studies available at high $P$. Symbols represent various studies; for Gt/melt (circles: Salters and Longhi (1999), diamonds: Salters et al. (2002), squares: Draper et al. (2003), up triangles: Suzuki et al. (2012), down triangles: Corgne et al. (2012)), for CPx/melt (squares: Salters and Longhi (1999), diamonds: Suzuki et al. (2012)), for Ol/melt (circle: Evans et al. (2008), squares: Salters et al. (2002), diamonds: Imai et al. (2012)). Error bars are taken from references where possible and for those not shown are smaller than the symbol size. 
element coordination changes have been reported in silicate melts at high pressure, including Si-O coordination change from 4 to 6 above 15-35 GPa (Sanloup et al., 2013; Sato and Funamori, 2010) and the change in Al-O coordination from fully 4-fold coordination to 50\% 6-fold between 2-12 GPa (Drewitt et al., 2015; Yarger et al., 1995). However as yet no minor element incorporation in silicate melts has been studied in situ at high pressure. Simon et al. (2013) have investigated the local structural environment of Y in silicate glasses using Extended X-ray Absorption Fine Structure (EXAFS) at ambient conditions. They studied the bonding environment of $\mathrm{Y}$ within the same glasses as Prowatke and Klemme (2005) and discovered that increasing melt polymerisation leads to an increase in $\mathrm{Y}$ coordination from 6 to 8, with a corresponding increase in average bond distance from $2.28 \AA$ to $2.38 \AA$. Ponader and Brown (1989) observed a similar compositional variance for La with $C N_{\mathrm{La}-\mathrm{O}}$ increasing from 7 to 9 in the higher polymerised melt, with $r_{\mathrm{La}-\mathrm{O}}$ also lengthening from 2.42 to $2.59 \AA$. In contrast, Farges (1996) observed a constant CN of 6 for HFSE Zr in silicate glasses, at the exception of a minor amount of octahedral $\mathrm{Zr}$ in their most polymerised rhyolitic composition. All these studies suggest that an increase in REE coordination results in an increase in bond length and indicate that important structural changes within the melt, not just the crystal lattice, impact REE local structure and partitioning. Nevertheless, to date all these studies have been carried out on quenched glass systems and not in situ at the conditions of melt formation.

$\mathrm{X}$-ray diffraction at high pressure and temperature is a well-established technique for studying silicate liquid structures in situ (see the initial study by Funamori et al. (2004) to the current highest $P$ - $T$ range (Sanloup et al. (2013)) but has not previously been applied to trace element studies due to the low concentrations of trace elements $(<0.1 \mathrm{wt} \%)$ required to represent natural systems. X-ray diffraction has the benefit of providing information on both the short and medium range structure of the melt, including absolute distance and average coordination numbers, without relying on structural models. In this study we employ two end member melt compositions, silicic haplogranite and a 'model basalt' iron-free anorthite-diopside to monitor structural changes at high pressure and temperature that may affect the incorporation of $\mathrm{Lu}$ at $4000 \mathrm{ppm}$ concentration into the melt. 
Table 1: Compositions from electron microprobe analysis of both initial and recovered samples. HPG (haplogranite) and AnD (anorthite-diopside) compositions given in wt.\% oxide. Analyses are based on average of a minimum of 10 sample spots, standard deviations are shown in brackets. ${ }^{*}$ The low totals for the HPG composition are due to the presence of water in the sample and correspond well with the amounts added during synthesis.

\begin{tabular}{|c|c|c|c|c|}
\hline Oxide & HPG initial & HPG recovered & AnD Initial & AnD Recovered \\
\hline $\mathrm{SiO}_{2}$ & $71.6(7)$ & $73.2(4)$ & $48.8(5)$ & $46.9(7)$ \\
\hline $\mathrm{Al}_{2} \mathrm{O}_{3}$ & $10.5(3)$ & $10.7(1)$ & $14.7(2)$ & $14.4(4)$ \\
\hline $\mathrm{Na}_{2} \mathrm{O}$ & $3.3(3)$ & $3.6(2)$ & - & - \\
\hline $\mathrm{K}_{2} \mathrm{O}$ & $3.7(1)$ & $3.8(1)$ & - & - \\
\hline $\mathrm{MgO}$ & - & - & $10.2(2)$ & $14.2(2)$ \\
\hline $\mathrm{CaO}$ & - & - & $22.7(2)$ & $21.6(2)$ \\
\hline $\mathrm{Lu}_{2} \mathrm{O}_{3}$ & $3.9(1)$ & $3.9(1)$ & $3.6(1)$ & $3.3(1)$ \\
\hline Totals & $93.0 *(6)$ & $95.7^{*}(3)$ & $100.2(6)$ & $100.5(6)$ \\
\hline
\end{tabular}

\section{Experimental Methods}

\subsection{Glass Synthesis}

The haplogranite (HPG) and anorthite-diopside (AnD) glasses were synthesised by mixing appropriate amounts of reagent grade oxides $\left(\mathrm{SiO}_{2}, \mathrm{Al}_{2} \mathrm{O}_{3}, \mathrm{MgO}\right)$ and carbonates $\left(\mathrm{K}_{2} \mathrm{CO}_{3}, \mathrm{Ca}_{2} \mathrm{CO}_{3}, \mathrm{Na}_{2} \mathrm{CO}_{3}\right)$ from Alfa Aesar (Table 1). The corresponding degree of polymerization as expressed by the $\mathrm{NBO} / \mathrm{T}$ ratio is 0.4 for the $\mathrm{HPG}$ glass, and 1.28 for the AnD glass. The mixed powders were ground in an agate pestle and mortar and decarbonated via a slow ramp for 12 hours at $1273 \mathrm{~K}$, then fused at $1873 \mathrm{~K}$ in a platinum crucible for 1 hour. The molten glass was quenched by immediately placing the crucible into cold water. The glass was checked for homogeneity, crushed and reground under acetone and finally fused again three times. Lu was added in the form of high purity $\mathrm{Lu}_{2} \mathrm{O}_{3}(>99.99 \%)$ at the desired concentration (Table 1) to a portion of the ground glass in order to have both a doped and plain sample of each composition for comparison. This glass was crushed, re-ground, re-melted at $1873 \mathrm{~K}$ and re-fused three times to ensure homogeneous distribution of Lu. All glasses were free from bubbles and contained no signs of crystallisation. The samples were crushed to a fine homogeneous powder before being loaded. The samples were free from iron to minimize the number of elements with bond lengths between 2.2-2.4 $\AA$, as these overlap the Lu-O bond distance. 
In order to lower the melting temperature of the haplogranite to temperatures achievable in a resistively heated diamond anvil cell $(<1270 \mathrm{~K})$, water was added to the sample through high pressure addition in a piston-cylinder press. Platinum capsules were welded containing finely ground haplogranite with 8-10 wt. $\% \mathrm{H}_{2} \mathrm{O}$ and held for 4 hours at $2 \mathrm{GPa}$ and $1670 \mathrm{~K}$ to ensure full homogenisation. The samples were fast quenched by immediately cutting power to the press. Final totals of water were between 6-8\% over 4 runs as estimated from the recovered sample analysis (Section 2.3).

\subsection{X-ray Diffraction}

Two experimental methods were used to obtain structural data at high pressure and temperature conditions. 1) Measurements on HPG melts were carried out up to $8 \mathrm{GPa}$ and $1100 \mathrm{~K}$ using angle-dispersive x-ray diffraction in resistively heated diamond anvil cells (DACs) on beamline I-15 at the Diamond Light Source (Harwell Campus, UK). 2) Experiments on the AnD melts up to $8 \mathrm{GPa}$ and $2000 \mathrm{~K}$ were collected on beamline 16-BM-B, HP-CAT, at the Advanced Photon Source (Argonne National Laboratory, USA) by energy-dispersive x-ray diffraction. High $P-T$ conditions were generated by use of a Paris-Edinburgh press. Ambient temperature AnD glass data were collected using DACs on beamline 13-ID-D, GSECARS, at the Advanced Photon Source by angle-dispersive x-ray diffraction to ensure that the obtained structural data are not dependent on the type of pressure apparatus (Figure 4 top panel). Ambient pressure AnD glass data were collected on the PSICHE beamline at Synchrotron Soleil, Paris, France (for Lu doped AnD glass) and at P02.2 beamline at PETRA III synchrotron in Hamburg, Germany (for plain AnD glass).

To create the high temperature conditions in the DAC, we have used the internal heating technique developed by Fei and Mao (1994) using a Pt wire. Sample was loaded into the $250 \mu \mathrm{m}$ hole of a rhenium gasket previously indented to $90 \mu \mathrm{m}$ thickness. In order to access the highest possible $Q$-range, we used $70^{\circ}$ opening Boehler-Almax seats. Temperature was recorded by a K-type thermocouple placed on the very edge of the gasket indent as close to the sample chamber as possible. Thermocouples were previously calibrated using materials of known melting temperature $\left(\mathrm{Pb}\right.$ and $\left.\mathrm{Na}_{2} \mathrm{CO}_{3}\right)$ in order to constrain the error in temperature and the thermal gradient within the sample chamber. High energy x-rays $(0.2637 \AA$ wavelength) were used to achieve maximum signal intensity from the low scattering sample with a beam focussed to $70 \times 70 \mathrm{\mu m}^{2}$ ). Diffraction patterns were collected for the glass and melt for $60 \mathrm{~s}$ using a Perkin Elmer detector at each pressure point (Table 2), and a background dark image was collected 
after each measurement in order to subtract the inherent electronic noise of the detector. Pressure was determined before each experiment by ruby fluorescence and at high temperature it was monitored by a Pt foil inserted into the sample chamber. Diffraction on the Pt calibrant was collected for $10 \mathrm{~s}$ at each pressure before and during heating. For each loading, measurements were collected on the samples, and afterwards the gasket was unloaded and replaced in the cell in order to collect the background scattering signal.

A detailed description of the Paris-Edinburgh press experimental techniques and cell design can be found in Kono et al. (2014). The experimental conditions are detailed in Table 2 with pressure determined from the cell-volume change of the pressure transmitting medium in the form of an $\mathrm{MgO}$ cylinder. Temperature was estimated by previous power calibrations using this cell assembly (Kono et al. (2014)). This calibration also accounts for the effect on pressure of the distance between the sample and $\mathrm{MgO}$ ring at high temperature using the $P-V$ - T relation of $\mathrm{MgO}$ and elastic wave velocity measurements (Kono et al. (2010)). Diffraction patterns on the $\mathrm{MgO}$ were collected at room temperature and above the melting temperature. X-ray diffraction was collected for 2 hours using an energy-dispersive germanium solid-state detector at ten $2 \theta$ angles $\left(2^{\circ}\right.$, $\left.2.7^{\circ}, 3.5^{\circ}, 5^{\circ}, 7^{\circ}, 10^{\circ}, 15^{\circ}, 20^{\circ}, 27^{\circ}, 35^{\circ}\right)$ enabling coverage up to $20 \AA^{-1}$ in reciprocal space with $Q=4 \pi E \sin \theta / 12.398$, where $\mathrm{E}$ is the energy of the x-rays in keV up to $>100 \mathrm{keV}$

\subsection{Recovered Sample Analysis}

Recovered HPG quenched samples were polished for electron microprobe analysis at the EMMAC (The Edinburgh Materials and Micro-Analysis Centre), University of Edinburgh. Analyses were carried out using a CAMECA SX100 electron microprobe with an accelerating voltage of $15 \mathrm{keV}$ and $8 \mu \mathrm{m}$ beam size. Where glass was recovered the samples retained a stoichiometry nearly identical to their starting compositions (Table 1); therefore it is unlikely the samples underwent any major chemical change during the experiments and no loss of Lu. Back scattered electron images taken of the sample show no evidence for quench crystallisation and the sample appears glassy (Figure 2b). Bubbles are present in the HPG which is probably due to exsolution of water during quenching indicating that water remained in the sample during the experiment. The low microprobe totals (Table 1) for the HPG composition are due to the presence of water in the sample. Quenched AnD samples were analysed at the Centre de Microanalyse Camparis, University Pierre and Marie Curie. These results 

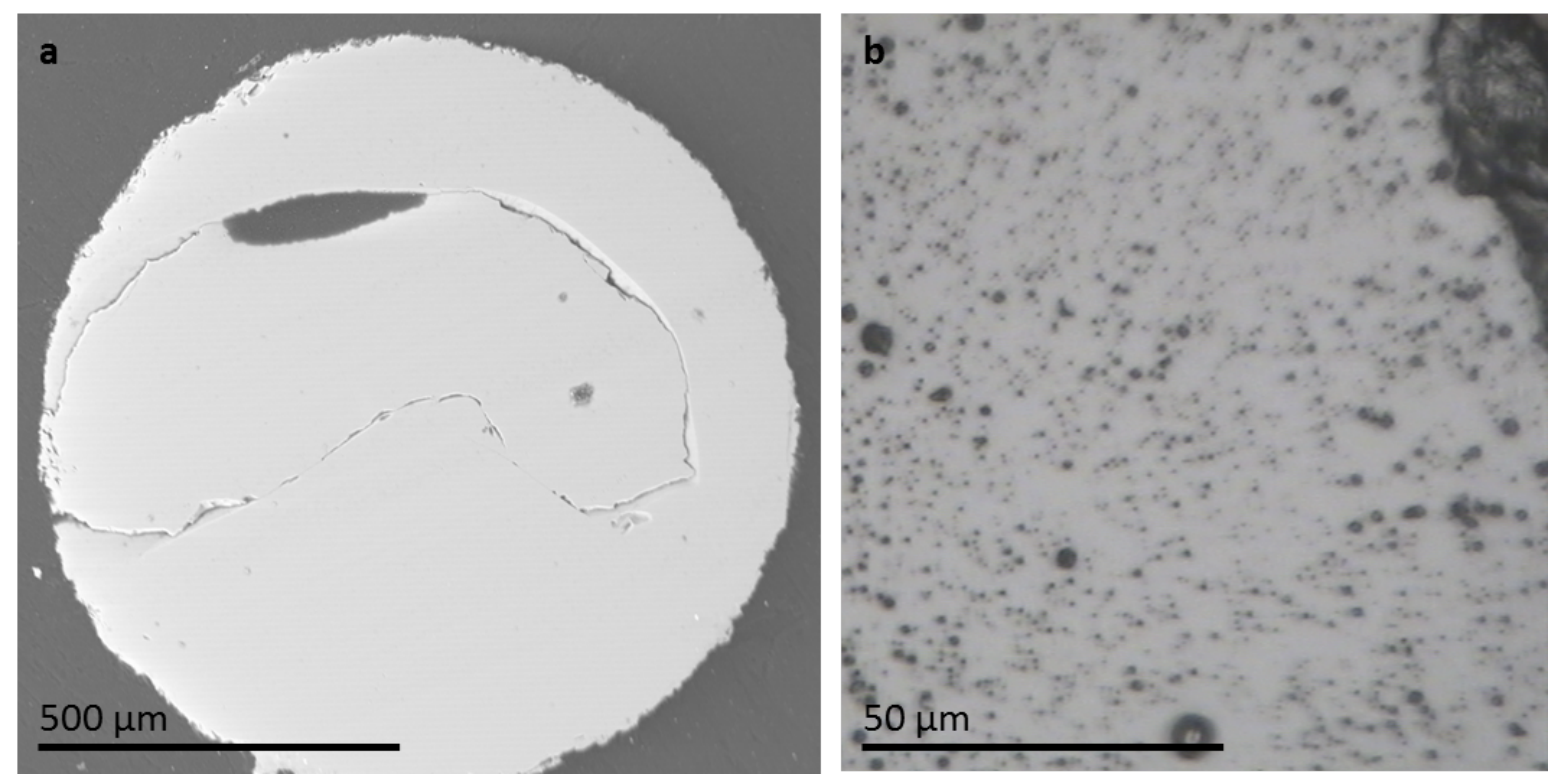

Figure 2: Left: Recovered sample from AnD experiment A8-a using a Paris-Edinburgh press. Right: Recovered sample from HPG experiment D8 from resistive heated DAC polished within Re gasket. Spots are bubbles within the hydrous sample.

(Table 1) show that when the sample quenched to a glass (Figure 2a) the composition after the experiment was nearly identical.

\subsection{Data Processing}

Angle-dispersive diffraction patterns were radially integrated using FIT2D (Hammersley (1996)), with a mask applied to crystalline Bragg peaks that arise from diffraction of the single crystal diamond anvils. The measured experimental intensity, $I(Q)$, contains scattering by both the sample and background contributions, where $Q=$ $\frac{4 \pi}{\lambda} \sin \theta$ and $\lambda$ is the x-ray beam wavelength. In order to isolate the intensity that contains only the structural information, corrections for background intensity, $I_{B}(Q)$, and attenuation, $A(Q)$, from the sample must be made to the measured intensity given by

$$
I(Q)=I_{s}(Q)+A(Q) I_{B}(Q)+I_{i n c}(Q)
$$

where $I_{s}(Q)$ represents the scattering from the sample containing only structural information, and $I_{\text {inc }}(Q)$ represents the incoherent scattering from the atoms, arising from the sum of the self $\sum_{\alpha} c_{\alpha} f_{\alpha}(Q)^{2}$ and Compton scattering $\sum_{\alpha} c_{\alpha} C_{\alpha}(Q)$, where $c_{\alpha}$ is the concentration of species $\alpha$. The values for the self and Compton scattering 
amplitudes are documented by Hajdu (1972); Hubbell et al. (1975). The Faber-Ziman total structure factor, $S(Q)$, (Faber and Ziman (1965)) is then determined by;

$$
S(Q)-1=\frac{K\left[I_{s}(Q)-A(Q) I_{B}(Q)\right]-I_{i n c}(Q)}{\left\langle f^{2}(Q)\right\rangle},
$$

where $K$ is required to normalise the data to the incoherent scattering profile and the total structure factor is normalised to the average scattering $\left\langle f^{2}(Q)\right\rangle=\left(\sum_{\alpha} c_{\alpha} f_{\alpha}(Q)\right)^{2}$. The radial distribution functions, $G(r)$, are then obtained from a Fourier transform of the $S(Q)$ as:

$$
G(r)-1=\frac{1}{2 \pi^{2} r n_{0}} \int_{0}^{\infty} Q[S(Q)-1] \sin (Q r) \mathrm{d} Q,
$$

where $n_{0}$ is the atomic density in atoms per $\AA^{3}$ and the experimental values are listed in Table 2. The densities were estimated by fixing $C N_{\mathrm{Si}-\mathrm{O}}=4$ and $d_{\mathrm{Si}-\mathrm{O}}=1.61 \AA$ and integrating under the Si-O contribution for each run (cf section 3.2 and Table 2), as well as applying self-consistency checks. These included ensuring the $S(Q)$ followed the sum rule $\int_{0}^{\infty}[S(Q)-1] Q^{2} d Q=-2 \pi n_{0}$, and that at low- $r$ any unphysical oscillations were minimised as $G(r=0)=0$ (Zeidler et al. (2009); Drewitt et al. (2013)).

For the energy dispersive x-ray diffraction data collected on HP-CAT, Bragg peaks arising from the diffraction of graphite in the cell assembly, and fluorescence of indium on the detector and $\mathrm{Lu}$ were removed at each angle. If peaks were at $>30 \%$ concentration between the energies of interest ( 25 to $55 \mathrm{keV}$ ) the data were discarded. Where required, fits were made to the data to extrapolate the signal after the Bragg peaks were removed. The aEDXD program developed by Changyong Park (see Kono et al. (2014)) was then used to scale the primary beam by least squares fitting at the highest $2 \theta$ angle, and an evenly spaced $S(Q)$ function was produced by error weighted spline smoothing of the merged data in $Q$-space. This technique is based on the highest diffraction angle oscillating around 1 because as $Q \rightarrow \infty, S(Q) \rightarrow 1$. The $G(r)$ was then obtained by Fourier Transform of the spline smoothened $S(Q)$ (Equation 3).

For the sake of comparison between EDX and ADX data, all $S(Q)$ were cut at $12 \AA^{-1}$ in order to have the same spatial resolution in the direct space on obtained $G(r)$. 
Table 2: $P$-T conditions of each experimental run as well as estimated densities and results on positions of the first two peaks in the $G(r), r_{1-2}$. Errors for $P$ and $T$ shown in brackets. Experiment 1 on HPG was carried out on I-15 at the Diamond Light Source. Where both glass and high $T$ data were collected, the density in [ ] is from the melt. Peak positions are shown only for high $T$ phases unless none were collected. ${ }^{*}$ on temperature indicates where the thermocouple failed during the run and a minimum $T$ was estimated from recrystallisation of $\mathrm{Pt}$ and previous thermocouple calibrations. Experiment 2: Collected on HP-CAT at the Argonne Photon Source in june 2014 (-a) and February 2016 (-b). ! represents where the 2nd peak arises from the O-O contribution producing a shoulder on the $\mathrm{r}_{3}$ peak. $\dagger$ denotes collection at synchrotron Soleil, PSICHE. $\ddagger$ denotes collection at Petra P.02 DESY.

\begin{tabular}{ccccccc}
\hline \hline Run no. & Comp. & $P(\mathrm{GPa})$ & $T(\mathrm{~K})$ & $n_{0}\left(\AA^{-3}\right)$ & \multicolumn{1}{c}{$G(r)$ positions $(\AA)$} \\
\hline Exp. 1 & & & & $r_{1}$ & $r_{2}$ \\
\hline D1 & HPG & $1.4(2)$ & 290 & 0.07 & 1.6 & - \\
D2 & HPG & $2.3(3)$ & $920(50)$ & $0.075[0.067]$ & 1.6 & - \\
D3 & HPG & $4.1(3)$ & 390 & 0.077 & 1.62 & - \\
D4 & HPG + Lu & $0.5(2)$ & $910^{*}(50)$ & $0.069[0.066]$ & 1.59 & 2.33 \\
D5 & HPG + Lu & $2.1(3)$ & $900^{*}(50)$ & {$[0.071]$} & 1.6 & 2.37 \\
D6 & HPG + Lu & $2.5(3)$ & 290 & 0.073 & 1.59 & 2.36 \\
D7 & HPG + Lu & $3.8(2)$ & $973(40)$ & $0.079[0.078]$ & 1.6 & 2.36 \\
D8 & HPG + Lu & $5.8(4)$ & $1073(40)$ & $0.083[0.082]$ & 1.59 & 2.35 \\
\hline \hline
\end{tabular}

Exp. 2

\begin{tabular}{ccccccc}
\hline Amb1 & AnD $(\dagger)$ & 0 & 290 & 0.081 & 1.62 & 2.41 \\
Amb2 & AnD + Lu $(\ddagger)$ & 0 & 290 & 0.081 & 1.62 & 2.36 \\
A1-b & AnD & $0.8(3)$ & $1570(50)$ & 0.082 & 1.59 & $2.78 !$ \\
A2-b & AnD & $2.4(2)$ & $1670(50)$ & 0.084 & 1.61 & $2.76 !$ \\
A3-b & AnD & $3.5(3)$ & $1720(50)$ & 0.087 & 1.59 & $2.76 !$ \\
A4-b & AnD & $4.8(3)$ & $1770(50)$ & 0.09 & 1.59 & - \\
A5-b & AnD & $6.5(3)$ & $1870(50)$ & 0.092 & 1.60 & - \\
A6-b & AnD & $8.0(4)$ & $2070(60)$ & 0.092 & 1.61 & - \\
A7-b & AnD $+\mathrm{Lu}$ & $0.8(3)$ & $1570(50)$ & 0.082 & 1.59 & 2.34 \\
A8-a & AnD $+\mathrm{Lu}$ & $2.1(3)$ & $2020(80)$ & 0.084 & 1.61 & 2.34 \\
A9-b & AnD $+\mathrm{Lu}$ & $3.1(3)$ & $1570(50)$ & 0.09 & 1.59 & 2.32 \\
A10-b & AnD $+\mathrm{Lu}$ & $4.2(3)$ & $1750(50)$ & 0.091 & 1.62 & 2.32 \\
A11-a & AnD $+\mathrm{Lu}$ & $5.2(3)$ & $1850(50)$ & 0.094 & 1.62 & 2.41 \\
A12-b & AnD $+\mathrm{Lu}$ & $7.0(3)$ & $2120(50)$ & 0.093 & 1.61 & 2.43 \\
\hline
\end{tabular}




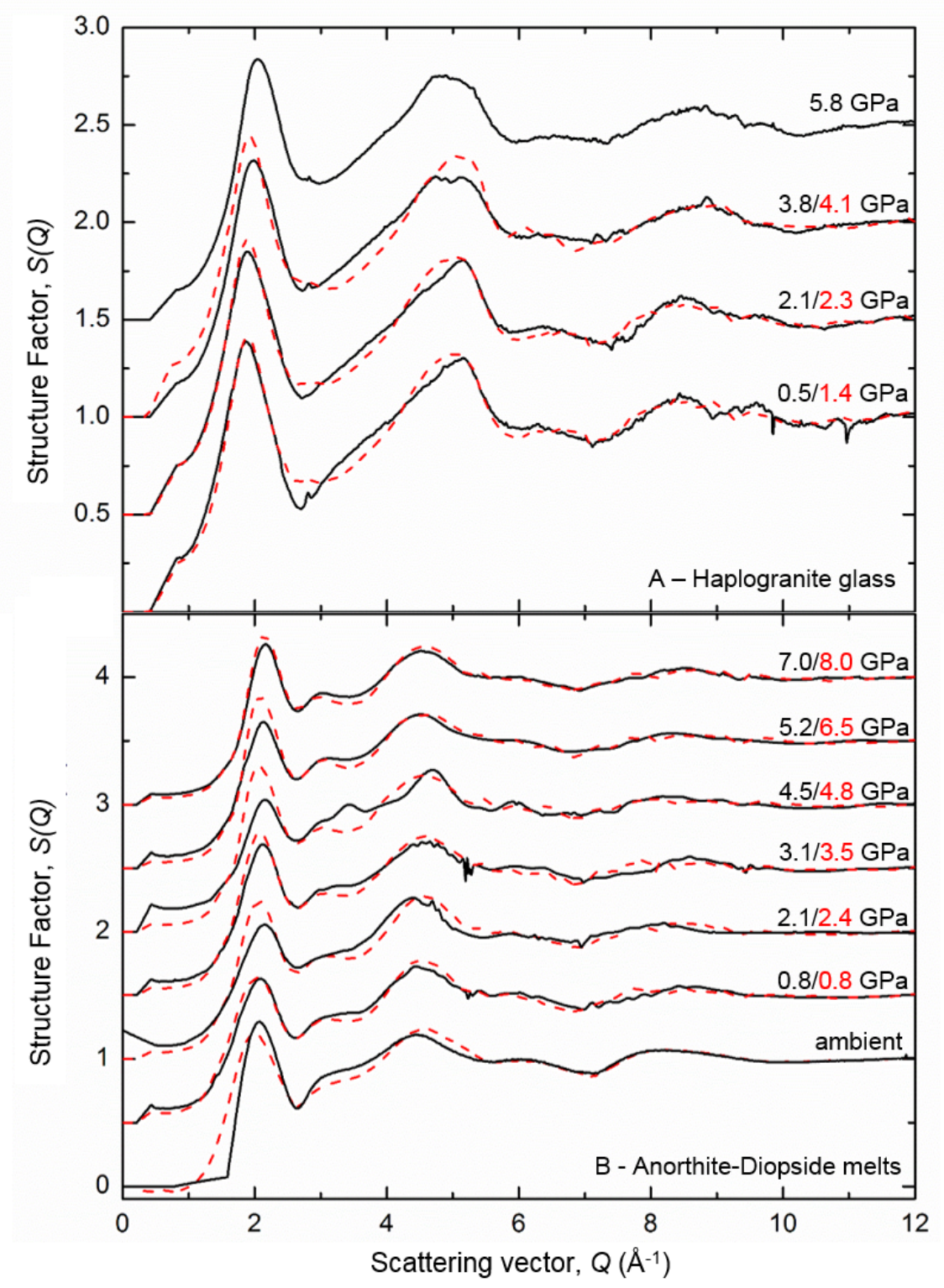

Figure 3: $S(Q)$ for samples listed in Table 2. Black solid lines show Lu doped samples and red dashed curves are the undoped samples at similar pressures. Top panel (A) shows HPG data with pressures shown for the Lu-doped measurements, and undoped glass spectra within $0.5 \mathrm{GPa}$ of these. Glass measurements are shown due to a lack of high- $T$ data at each $P$, however as discussed in Section 3.1, the HPG glass is analogous to the melt. Lower Panel (B) shows AnD melt experiments at $>1500 \mathrm{~K}$ and undoped samples are within $1 \mathrm{GPa}$ of given $P$. 


\section{Results}

\subsection{Overall structural description}

Ambient and high temperature data were collected on Lu-doped and undoped samples at similar pressure points and when possible, quench measurements were taken on all runs (Table 2). The $S(Q)$ and $G(r)$ are shown in Figures 3 and 4. During heating HPG samples, at temperatures $>850 \mathrm{~K}$ the samples either recrystallised or remained amorphous due to the strong glass forming nature of $\mathrm{SiO}_{2}$-rich liquids. On these time scales ( $>1$ hour) recrystallization would be expected to occur above the glass transition temperature at $\sim 850 \mathrm{~K}$ (Dingwell, 1998). Therefore, if recrystallization did not occur at these temperatures, the samples were in the super-cooled liquid state. Two experiments (D2 and D7) were conducted at $T$ exceeding the liquidus temperature for haplogranite (Holtz et al. (1992)). From our results, the local environment of $\mathrm{Lu}$ in the melt phase and the ambient temperature glass phase are identical as no changes were observed in the corresponding $G(r)$ (grey and red solid lines on Figure 4). In Figure $3 \mathrm{~A}$ the first sharp diffraction peak (FSDP) is seen at $1.98 \AA^{-1}$ at $0.5 \mathrm{GPa}$-room $T$ with little change over the $P$-range presented here (up to $2.01 \AA^{-1}$ at $5.8 \mathrm{GPa}$-room $T$ ). This is higher than in the dry HPG glass where the FSDP is at $1.67 \AA^{-1}$ and reflects the depolymerisation of the glass induced by water (Anderson et al., 2014), an effect also reported by forsterite-enstatite melts (Yamada et al., 2007). Alteration to the $S(Q)$ from the scattering of $\mathrm{Lu}$ is seen in the $2 \mathrm{nd}$ peak between $3-5 \AA^{-1}$, where the peak appears less broad in the Lu-doped case with slightly greater intensity on the upward slope at $3-4 \AA^{-1}$.

The measured $S(Q)$ for the Lu doped AnD compositions are shown in the lower panel (B) of Figure 3 along with undoped samples for comparison. The FSDP shows a gradual increase from 2.05 to $2.1 \AA^{-1}$ from ambient conditions to $7 \mathrm{GPa}$. An increase in the FSDP has been seen for other silicate glass and melt compositions and is attributed to the collapse of open cages in the $\mathrm{SiO}_{2}$ network (Benmore et al. (2010); Meade et al. (1992)). A similar increase in intensity between $3-4 \AA^{-1}$, as observed in the HPG, is seen in the Lu-doped $\operatorname{AnD} S(Q)$.

The resulting real space distribution functions, $G(r)$, are shown in Figure 4B. The main peak positions, atomic densities and uncertainties in real space for each data point are detailed in Table 2. In both compositions the first peak in the $G(r), r_{1}$, is attributed to the $d_{\mathrm{Si}-\mathrm{O}}$ at 1.61(2) $\AA$ with 4-fold coordination as shown in other silicate glass, liquid and crystalline structures (Sato and Funamori (2010); Meade et al. (1992)). 


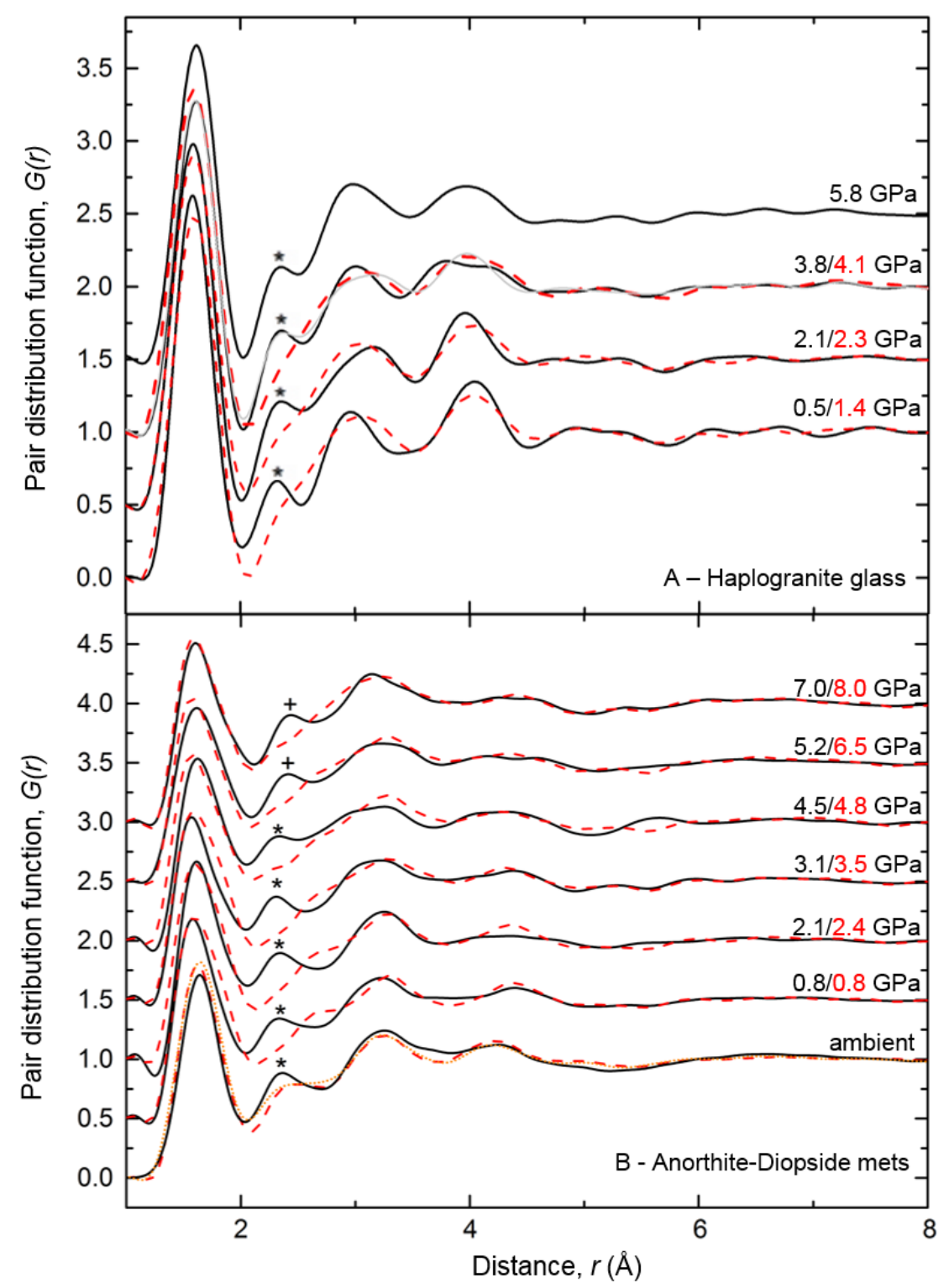

Figure 4: Radial distribution functions from the $S(Q)$ shown in Figure 3 and detailed in Table 2. Black solid lines are Lu-doped and red dashed are undoped samples as described in Figure 3. In the HPG (A) grey solid line was collected at high- $T$ and show the similarity between molten high $P$ HPG samples and their respective glass. * highlights the effect of Lu-O on the $G(r)$ and $r_{2}$ position. In the $\mathrm{AnD}(\mathrm{B})$, at $>5 \mathrm{GPa}$, the + marks where the peak shifts to higher $r$. In the AnD (B) dotted orange line was collected using a DAC at room $T$ and is similar to the $G(r)$ obtained using a PE cell. 
In the HPG, the second peak, $r_{2}$, only appears within the doped samples (D4-D8) at 2.36 (3) $\AA$ and is attributed to the Lu-O bond distance. In the undoped $\mathrm{AnD}$, the second contribution arises from the Ca-O correlations at $\sim 2.4 \AA$ and overlaps the Lu$\mathrm{O}$ distance. However the $r_{2}$ peak in the doped AnD can be clearly seen to increase in intensity and shift to lower $r$ with the introduction of $\mathrm{Lu}$ in the ambient samples (Figure 4B). The correlations observed at 3.0(2) $\AA$ in the HPG and 3.2(3) $\AA$ in the $\mathrm{AnD}$ are attributed to the sum of the O-O and $\mathrm{Si}-\mathrm{Si}$ contributions and match well with $G(r)$ observed in other studies (Crépisson et al. (2014); Sanloup et al. (2013)) and with MD simulations by Vuilleumier et al. (2009) on similar compositions. In the HPG, this correlation sharpens in the presence of Lu, potentially reflecting increased ordering of the Si-Si distribution, an effect not observed for the $\mathrm{AnD}$ melts within the noise level. In the HPG a fourth correlation is visible at $4 \AA$, this can be attributed to the 2nd interaction of Si-O and is much more pronounced in the HPG due to the higher concentration of $\mathrm{SiO}_{2}$.

\subsection{Fit of the Lu-O contribution}

The radial distribution function $G(r)$ is the sum of all the individual ion-ion interactions within the sample, where each individual Gaussian, $g(r)_{\text {ind }}$, represents a single ion-ion contribution. This was fit using the following relations:

$$
G(r)=\sum g(r)_{\mathrm{ind}}=\frac{1}{n_{0} S_{\infty}} \sum_{i} \frac{x_{i} A_{i}}{\sigma_{i} \sqrt{2 \pi}} \exp \left(\frac{-\left(r-d_{i}\right)^{2}}{2 \sigma_{i}^{2}}\right)
$$

where;

$$
A_{i}=\frac{C N_{i}}{\int \frac{4 \pi r^{2}}{\sigma_{i} \sqrt{2 \pi}} \exp -\left(\frac{\left(r-d_{i}\right)^{2}}{2 \sigma_{i}^{2}}\right) d r} .
$$

The coordination number for the individual ion-ion contributions, $C N_{i}$, is related to the integral under each individual Gaussian by the density, $n_{0}$, and concentration, $x_{i}$, of the species. The interatomic distance is $d_{i}$ and $\sigma_{i}=k \sqrt{d_{i}}$ defines the width of the Gaussian using an adjustable parameter $k$ (Hosemann and Bagchi (1962)), with values ranging from 0.07 to 0.2 depending on the ion-ion contribution. Over this pressure and temperature range it is assumed that the $\mathrm{Si}-\mathrm{O}$ coordination, $C N_{\mathrm{Si}-\mathrm{O}}$, of 4 and bond length, $r_{\mathrm{Si}-\mathrm{O}}$, of $1.61 \AA$ remain unchanged (Benmore et al. (2010); Sanloup et al. (2013); Sato and Funamori (2010)). Other known peak positions, i.e. Al-O for HPG and Al-O, $\mathrm{Mg}-\mathrm{O}$ and $\mathrm{Ca}-\mathrm{O}$ for $\mathrm{AnD}$, and coordination numbers are taken from literature (Guillot 

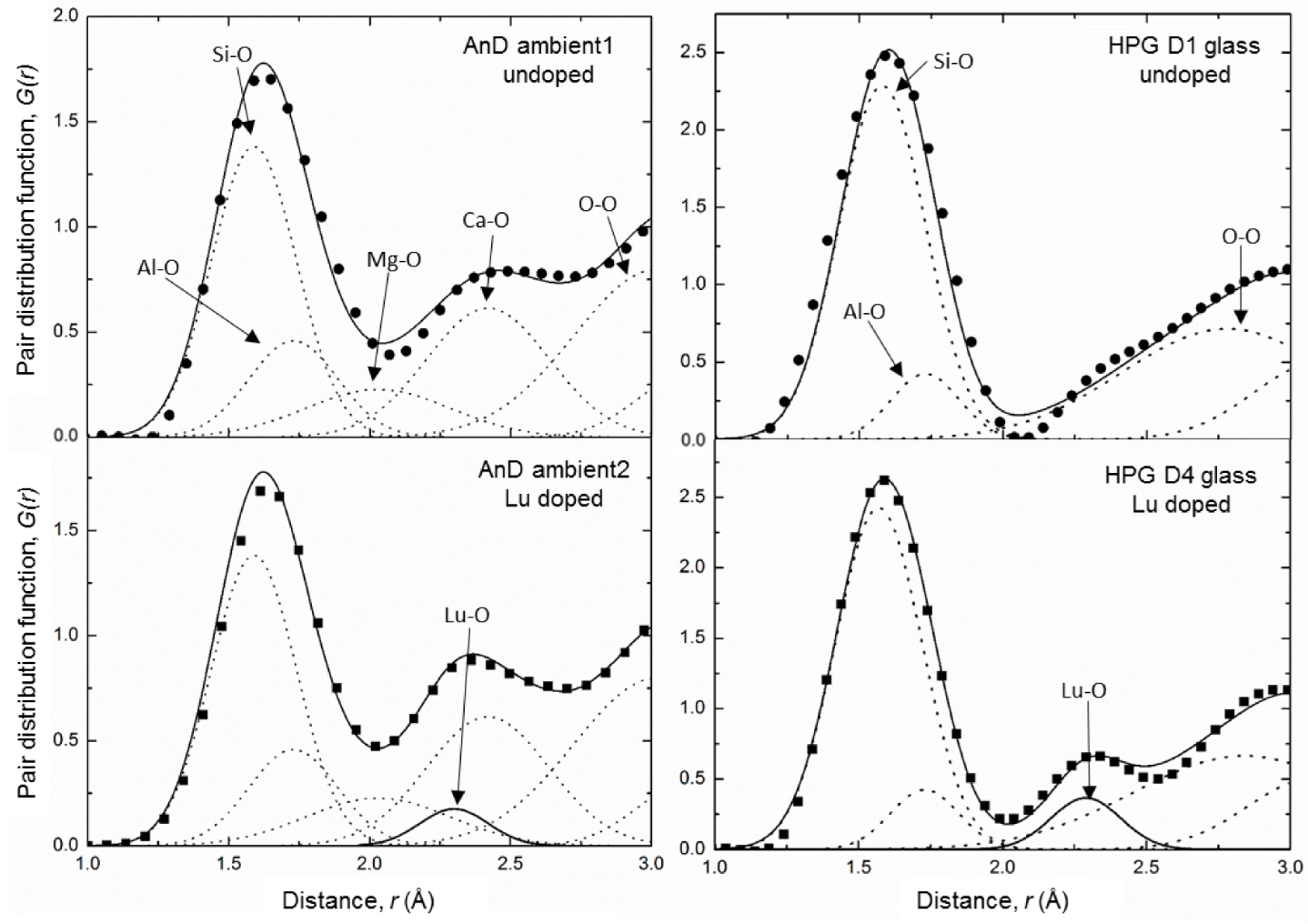

Figure 5: Measured $G(r)$ (black markers) from Figure 4 shown with Gaussian fits to both the plain (upper panels) and doped (lower panels) samples. Individual Gaussians, $g_{\text {ind }}(r)$, for ion-ion contributions are labelled (dotted lines) along with the total sum of Gaussians (solid black line). Left panels show the AnD compositions and right panels, the HPG. Lu-O contributions are shown in the doped figures by a thick black line and are labelled as Lu-O. Major element fit parameters are identical between the doped and undoped samples using parameters described in Table 3. 
Table 3: Ion-ion contributions used to model individual Gaussians, $g(r)$ ind for both compositions. * indicates values taken from references cited in the text, all others are fitted. The coordination numbers obtained for $\mathrm{Lu}$ are an average over a minimum of 10 fits with error of \pm 0.3 for each final value. $d_{i}=$ bond length, $C N_{i}=$ coordination of individual bond. '-' indicates that the value is identical to above mentioned.

\begin{tabular}{|c|c|c|c|c|c|c|c|c|c|}
\hline \multicolumn{10}{|c|}{$P$-independent contributions } \\
\hline \multicolumn{5}{|c|}{$\mathrm{HPG}$} & \multicolumn{5}{|c|}{$\mathrm{AnD}$} \\
\hline & \multicolumn{2}{|c|}{$\mathrm{Si}-\mathrm{O}$} & \multicolumn{2}{|c|}{$\mathrm{Lu}-\mathrm{O}$} & & \multicolumn{2}{|c|}{$\mathrm{Si}-\mathrm{O}$} & \multicolumn{2}{|c|}{$\mathrm{Mg}-\mathrm{O}$} \\
\hline & $d_{i}$ & $C N_{i}$ & $d_{i}$ & $C N_{i}$ & & $d_{i}$ & $C N_{i}$ & $d_{i}$ & $C N_{i}$ \\
\hline & $1.6(2)$ & $4^{*}$ & $2.36(3)$ & 8.1 & & $1.6(2)$ & $4^{*}$ & $2.00(5)$ & $5^{*}$ \\
\hline \multicolumn{10}{|c|}{$P$-dependent contributions } \\
\hline \multicolumn{3}{|c|}{ HPG } & \multicolumn{7}{|c|}{$\mathrm{AnD}$} \\
\hline $\mathrm{P}$ & \multicolumn{2}{|c|}{$\mathrm{Al}-\mathrm{O}$} & $\mathrm{P}$ & \multicolumn{2}{|c|}{$\mathrm{Al}-\mathrm{O}$} & \multicolumn{2}{|c|}{$\mathrm{Ca}-\mathrm{O}$} & \multicolumn{2}{|c|}{$\mathrm{Lu}-\mathrm{O}$} \\
\hline$(\mathrm{GPa})$ & $d_{i}$ & $C N_{i}$ & $(\mathrm{GPa})$ & $d_{i}$ & $C N_{i}$ & $d_{i}$ & $C N_{i}$ & $d_{i}$ & $C N_{i}$ \\
\hline 0.5 & $1.73(1)$ & $4.1^{*}$ & 0.8 & $1.73(1)$ & $4.3^{*}$ & $2.40(2)$ & $7^{*}$ & $2.29(2)$ & 6.2 \\
\hline 2.1 & - & $4.1^{*}$ & 2.1 & - & $4.5^{*}$ & - & $7.2^{*}$ & $2.32(2)$ & - \\
\hline 2.5 & - & $4.2^{*}$ & 3.1 & - & $4.5^{*}$ & - & $7.4^{*}$ & $2.30(2)$ & - \\
\hline 3.8 & - & $4.4^{*}$ & 4.5 & - & $4.6^{*}$ & - & $7.6^{*}$ & $2.32(2)$ & - \\
\hline \multirow[t]{2}{*}{5.8} & - & $4.6^{*}$ & 5.2 & - & $4.7^{*}$ & - & $8.2^{*}$ & $2.39(2)$ & 7.9 \\
\hline & & & 7.8 & - & $4.9^{*}$ & - & $8.3^{*}$ & $2.41(2)$ & - \\
\hline
\end{tabular}

and Sator (2007a,b); Sun et al. (2011); Drewitt et al. (2015), and listed in Table 3). Na contribution is insignificant to the total $G(r)$ due to its light scattering so is not shown here, as in rhyolitic $G(r)$ models by Vuilleumier et al. (2009). Bond distances above $3 \AA$ (e.g. K-O, Si-Si) do not contribute to the signal below the Lu-O contribution and were fitted as a single contribution.

Initially the undoped data for each pressure are fitted with a sum of Gaussians to obtain interatomic distances for major element ion-ion contributions at $r<2.5 \AA$ along with the O-O contribution (Figure 5), and the same parameters are used to fit the Ludoped data. This results in the isolation of the fit parameters required for $C N_{\mathrm{Lu}-\mathrm{O}}$ and $d_{\mathrm{Lu}-\mathrm{O}}($ Table 3 and Figure 5 ). This technique limits the uncertainty that arises from fitting complex pair distribution functions but errors in the average coordination arise from the asymmetry of the real $g(r)_{\text {ind }}$ correlations and their high $r$ oscillations. 


\subsection{Lutetium incorporation}

In the HPG melt, a bond distance $r_{\mathrm{Lu}-\mathrm{O}}=2.36(3) \AA$ was observed and found to be invariable with pressure within the accuracy of this technique. The average $C N_{\mathrm{Lu}-\mathrm{O}}$ was determined to be 8.1(3) at all pressure and temperature conditions. For the AnD a $C N_{\mathrm{Lu}-\mathrm{O}}$ of $6.2(3)$ and a $r_{\mathrm{Lu}-\mathrm{O}}$ of $2.29(2) \AA$ were determined for the lowest pressure data $(<5 \mathrm{GPa})$ and the ambient doped glass. The higher pressure points show a clear shift in fit correlation to a higher $r_{\mathrm{Lu}-\mathrm{O}}$ of 2.40 (3) $\AA$ and an estimated $C N_{\mathrm{Lu}-\mathrm{O}}$ of 7.9 (3) (Table 3, Figure 6). This change appears to be abrupt, occurring within $1 \mathrm{GPa}$ (from the accuracy of our data points), and it only affects the Lu-O contribution. This is unlike major element coordination changes which undergo a transition over a broad pressure range (Sato and Funamori (2010); Drewitt et al. (2015); Yarger et al. (1995)). At two pressure points data were also collected at three temperatures over a $400 \mathrm{~K}$ range (Supplementary Material). The Lu-O contribution in AnD seems unaffected by $T$ at least within the uncertainties of the method, i.e. $0.2 \AA$ on bond length and 0.2 on the coordination number.

Crystalline oxide bond lengths for Lu-O are in good agreement with the distance of the $r_{2}$ correlation at ambient pressure. Six-fold coordinated Lu-O in oxides is reported to be $2.24 \AA$ and 8-fold coordinated Lu-O at $2.32 \AA$ which agree with tabulated ionic radii by Shannon (1976). Studies on other REE glasses, e.g. YbSiAlO/N, have found similar parameters with $\mathrm{Yb}-\mathrm{O}$ coordination at 6 and a bond length of $2.22 \AA$ (Uhlig et al. (1998)). Other REE-O such as Dy and La in sodium silicates show decreasing bond length with atomic radii due to the lanthanide contraction, with 6-fold Dy-O at $2.29 \AA$ and La-O at $2.48 \AA$. In this study, a coordination $C N_{\mathrm{Lu}-\mathrm{O}}$ of 6 gives rise to a bond distance of $2.29 \AA$, and $C N_{\mathrm{Lu}-\mathrm{O}}$ of 8 gives $2.36-2.4 \AA$, as might be expected in the liquid this distance is slightly longer than those of the solids.

\section{Discussion}

To our knowledge this is the first experimental study of its kind to identify the structural incorporation of trace elements in situ within a silicate melt structure at high pressure, previous EXAFS data having been measured on glasses at ambient conditions. As the ambient pressure results presented for $C N_{\mathrm{Lu}-\mathrm{O}}$ in glasses corroborate coordinations and bond lengths of $\mathrm{Y}$, a geochemical proxy for Lu but with a lower absorption K-edge energy that makes it suitable for EXAFS analysis (Simon et al., 2013), this method appears to provide a reliable tool for determining REE speciation 

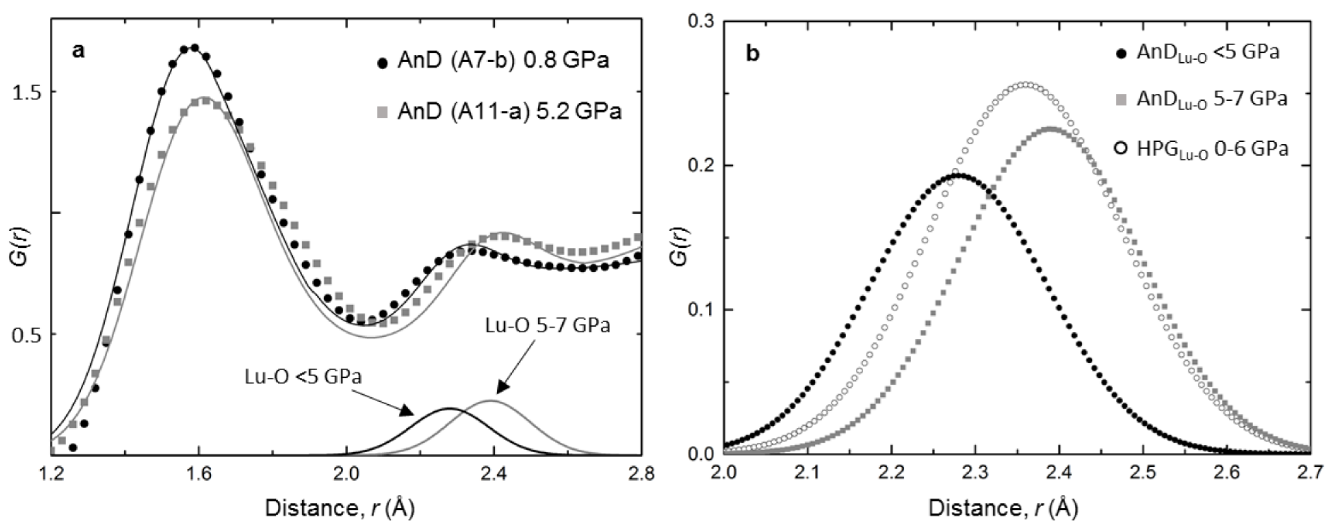

Figure 6: a) Change in fits for $\mathrm{Lu}-\mathrm{O}$ in $\mathrm{AnD}$ with $P$ increase above $5 \mathrm{GPa} . G(r)$ for a low $P \mathrm{AnD}$ melt (black circles) and high $P$ AnD melt above the Lu-O coordination change (grey squares) and their respective fits (solid lines) are shown. Individual $g(r)_{\mathrm{Lu}-\mathrm{O}}$ are marked with a clear shift to higher $r$ seen above $5 \mathrm{GPa}$. b) Individual $g(r)_{\mathrm{Lu}-\mathrm{O}}$ for low $P \mathrm{AnD}$ (black circles), high $P$ AnD (grey squares) and average for HPG (high silica) over the $P$ range studied (open circles).

within silicate melts. A major consideration for this technique is that it is reliant on the applicability of Henry's law as in order to use trace elements in models it is assumed that the activity, and hence partitioning of trace elements, is independant of concentration below a given limit. This is because at such low concentrations they form an insignificant structural part of a phase and do not alter the thermodynamics of the system. Although Lu here is not at natural levels of concentration $(<2 \mathrm{ppm})$, in this system we propose that Henry's law is still obeyed as: 1) At concentrations of $4000 \mathrm{ppm} \mathrm{Lu}$ ions are highly unlikely to interact with each other. 2) Many studies on partitioning of trace elements have shown that Henry's law is still obeyed even at several wt. \% concentration of trace elements (Beattie (1993); Prowatke and Klemme (2006)). 3) There is a close similarity here with other results on REE (La, Gd and $\mathrm{Yb}$ ) at much lower concentrations (Ponader and Brown, 1989).

\subsection{Compositional effect}

At low pressure, $<5 \mathrm{GPa}$, the results presented show an increase in Lu coordination from 6 to 8 with increasing silica content of the melt, from AnD to HPG, coincident with an increase in bond length of 0.07 (3) $\AA$ (Figure 6b). This is consistent with observations on $\mathrm{Y}-\mathrm{O}$ in silicate and aluminosilicate glasses at ambient conditions (Simon et al. (2013)), and MD calculations on Y-O in aluminosilicate melts (Haigis et al., 2013). 
As discussed in the introduction, this compositional effect is attributed to the higher availability of non-bridging oxygens in the basaltic network due to the presence of oxygens weakly bonded to Ca atoms (Haigis et al., 2013). This is reflected in the narrower distribution around a shorter mean Lu-O distance calculated for less polymerised melts (Haigis et al., 2013) and observed in the present work (Figure 6b and width parameters reported in Table 3). The results for the HPG presented here are all for a hydrous composition. We measure the same Lu-O coordination number in our hydrous composition than reported in dry silicate glasses for Y (Simon et al., 2013). This indicates that the absence of water would not affect our results. Since water de-polymerises the melt structure (Mysen et al., 1980) as can been seen by the shift of the first sharp diffraction peak to high $Q$-values initially reported for hydrous forsterite-enstatite melts (Yamada et al., 2007) and observed here as well (cf section 3.1), this in turn implies that Lu does not enter the ring structure as expected from its large size.

\subsection{Pressure effect}

Within the HPG there is no observable pressure effect on $\mathrm{Lu}$ incorporation within the melt structure up to $8 \mathrm{GPa}$. Silica rich melts are predominantly comprised of interconnected rings of tetrahedra that form cages (Kohara et al., 2011). As pressure increases these collapse as the network is compressed and reaches a packing limit around $5 \mathrm{GPa}$ (Wang et al., 2014). However as Lu is unlikely to be accommodated within the cages there is little compressional effect on its speciation within the melt. Within the AnD, however, an increase in $P$ causes an abrupt coordination increase between 4$5 \mathrm{GPa}$, accompanied by an increase in the bond length from 2.29 to $2.40 \AA$ (Figure 6). Therefore above $5 \mathrm{GPa}$ the $C N_{\mathrm{Lu}-\mathrm{O}}$ and $r_{\mathrm{Lu}-\mathrm{O}}$ are similar to that of the HPG. At high pressures, as the packing limit of the melt is reached, Lu is forced onto 'crystal-like' sites and coordination increases. The presence of these 'crystal-like' sites in the melt was suggested by van Westrenen et al. (2000), who suggested that oxide like, $\mathrm{J}_{2} \mathrm{O}_{3}$, and garnet like, $\mathrm{J}_{3} \mathrm{Al}_{5} \mathrm{O}_{12}$, sites might exist in the melt structure and influence partition coefficients due to the site elasticity and radii. van Westrenen et al. (2000) showed that partitioning behaviour between silicate melt and garnets could be better explained by the presence of $\mathrm{J}_{3} \mathrm{Al}_{5} \mathrm{O}_{12}$ sites with 8-fold coordination within the melt, rather than 6fold $\mathrm{J}_{2} \mathrm{O}_{3}$ sites. As pressure increases and the melt is packed more closely together it is likely that more 'crystal-like' sites are created within the melt with a higher coordination environment. These have a similar bonding environment to sites within minerals such as garnet and therefore a reduction at high $P$ in partition coefficient between the melt and 
minerals, where $\mathrm{REE}^{3+}$ are usually compatible, would be expected. It is also interesting to note that $\mathrm{Ca}$ atoms, that constitute the second shell of neighbours around Lu after O atoms in depolymerised melts (Haigis et al., 2013), get progressively bonded to more $\mathrm{O}$ atoms in the 0-10 GPa interval with a Ca-O coordination number increasing from 7 to 9 (Guillot and Sator, 2007a; Sun et al., 2011; Drewitt et al., 2015).

\subsection{Impact on Partition Coefficients}

The coordination change from 6 to 8 as melt polymerisation increases (i.e. from the AnD to the HPG) corresponds with results presented by Prowatke and Klemme (2005) and Schmidt et al. (2006) on the dramatic increase in REE partition coefficients with melt polymerisation. This increase in compatibility and preference to incorporate in the mineral as polymerisation of the melt increases has been proposed to be due to the energetics associated with bonding to predominantly bridging oxygens. In depolymerised melts the large sites and freely available non-bridging oxygens mean that at lower $P$ the REEs can more easily incorporate into the melt structure than in the crystal lattice. Although we find that $\mathrm{Lu}$ has the same coordination in polymerised melts as the basaltic melts at $>5 \mathrm{GPa}$, existing partitioning studies would suggest that the site or mechanism for Lu incorporation in these melts is different as opposite partitioning behaviour is observed (between low pressure basaltic and granitic melts an increase in $D_{\mathrm{Lu}}$ is witnessed, but a decrease in $D_{\mathrm{Lu}}$ between low pressure and $>5 \mathrm{GPa}$ basaltic melts).

From these results we propose that in basaltic systems, the melt has a much stronger influence on $D^{\mathrm{min} / \mathrm{melt}}$ with pressure than previously expected. The observed decrease in compatibility with $P$ (Figure 1) could occur in relation with the observed change of local structural environment of $\mathrm{Lu}$ in the melt. The coordination change in the melt at $5 \mathrm{GPa}$ results in the plateauing of the $D_{\mathrm{REE}}^{\mathrm{min} / \mathrm{melt}}$ as there is little preference for either the mineral or melt at this pressure. This change of local structural environment most likely implies a variation of the volume change of the partitioning reaction between mineral and melt. This is consistent with the previous findings from Corgne et al. (2012) who attributed the factor of 2 mismatch between their measured $D_{\mathrm{REE}}^{\text {garnet }} /$ melt and those predicted by the van Westrenen\&Draper (2007) model to the $P$-dependence of the reaction volume change that is not accounted for.

In other words, the change of local environment of Lu in melts implies that both the pre-exponential term, $D_{0}$, and site elasticity terms be revised in the lattice strain models to explicitly model not only the crystal part but also the melt contribution to element 
partitioning. Structural changes in the melts have been advocated to explain the abrupt changes in the $P$-dependence of $D^{\text {magma/metal }}$ for $\mathrm{Ni}$, Co, W circa $5 \mathrm{GPa}$ (Kegler et al., 2008; Cottrell et al., 2009; Keppler and Rubie, 1993; Sanloup et al., 2011) and 35 GPa (Sanloup, 2016). The observed change of $P$-dependence of $D^{\text {magma/metal }}$ for $\mathrm{Ni}, \mathrm{Co}$, $\mathrm{W}$, of $D_{\mathrm{Lu}}^{\mathrm{mineral} / \mathrm{melt}}$ for garnet, clinopyroxene and olivine/melt systems above $5 \mathrm{GPa}$ can either be a mere coincidence, or suggest instead an important structural control from the silicate melt. The comparison of molten basalt density with crystalline basalt (i.e. eclogite) density shows that the large crystal-melt density difference at room $P$ is divided by 3 at $5 \mathrm{GPa}$, and almost vanishes above $50 \mathrm{GPa}$ (Sanloup, 2016). The structural control of magmas on element partitioning may thus occur through both abrupt changes of coordination number as reported here for $\mathrm{Lu}$, and through large changes of melt compressibility.

\section{Conclusions}

This study shows that x-ray diffraction techniques can be used to study trace element incorporation in liquids at high pressure and can reliably determine the nearestneighbour bond distances for minor elements. Our results show an increase in coordination from 6 to 8 of Lu with increasing polymerisation of the melt, consistent with an increase in the $D^{\text {mineral/melt }}$ partitioning ratio from $<1$ to $>100$. These results are consistent with other studies carried out on $\mathrm{Y}, \mathrm{Zr}$, Th and La with changing glass polymerisation. This data suggest that the coordination of REE in highly polymerised compositions is similar in the glass and melt and also remains constant up to 6 GPa.

An abrupt coordination increase from 6 to 8 is observed at $4-5 \mathrm{GPa}$ in less polymerised systems. This coordination change suggests that at $>5 \mathrm{GPa}$ compression of the melt results in the formation of 'crystal like' sites that accommodate Lu at high pressure. This change in Lu incorporation is likely to strongly affect the partitioning of $\mathrm{Lu}$ at depth, as is the increased stiffness of magmas at high pressures.

Overall these results indicate that not only composition but also pressure induces structural changes in the melt that underpin drastic changes in REE partitioning, and subsequently cause distinct changes in the predicted Lu/Hf ratios from deep magmas. As the melt structure changes with pressure, using a single melt term to normalise the effects of melt on trace element partitioning will not accurately predict partitioning behaviour at depth during magma formation or differentiation. In order to fully understand how partitioning is affected by melt structural changes, standard models should 
be implemented with detailed insight into the exact geometry and elasticity of the REE sites within the melt network with varying pressure.

\section{Acknowledgements}

C.D.G. was supported by EPSRC for PhD studentship funding with the Condensed Matter Doctoral Training Centre (CM-CDT) under grant number EP/G03673X/1. We thank Diamond Light Source for access to beamline I-15 (proposal EE9022-1) that contributed to some of the results presented here. Portions of this work were performed at HPCAT (Sector 16), Advanced Photon Source (APS), Argonne National Laboratory. HPCAT operations are supported by DOE-NNSA under Award No. DE-NA0001974 and DOE-BES under Award No. DE-FG02-99ER45775, with partial instrumentation funding by NSF. The Advanced Photon Source is a U.S. Department of Energy (DOE) Office of Science User Facility operated for the DOE Office of Science by Argonne National Laboratory under Contract No. DE-AC02-06CH11357. We thank N. Guignot on PSICHE beamline at Soleil and Z. Konôpková on P02.2 at PETRAIII. This work was supported by the European Research Council under the European Community's Seventh Framework Programme (FP7/20072013 Grant Agreement No. 259649 to C. Sanloup). We thank G. Bromiley for his help in proofreading this manuscript. 


\section{References}

Anderson, A. J., Yan, H., Mayanovic, R. A., Solferino, G., Benmore, C. J., 2014. Highenergy X-ray diffraction of a hydrous silicate liquid under conditions of high pressure and temperature in a modified hydrothermal diamond anvil cell. High Press. Res. 34 (1), 100-109.

Beattie, P., 1993. On the occurrence of apparent non-Henry's law behaviour in experimental partitioning studies. Geochim. Cosmochim. Acta 57, 47-55.

Benmore, C. J., Soignard, E., Amin, S. A., Guthrie, M., Shastri, S. D., Lee, P. L., Yarger, J. L., 2010. Structural and topological changes in silica glass at pressure. Phys. Rev. B 81, 054105.

Blundy, J., Wood, B. J., 1994. Prediction of crystal-melt partition coefficients from elastic moduli. Nature 372, 452-454.

Corgne, A., Armstrong, L. S., Keshav, S., Fei, Y., McDonough, W. F., Minarik, W. G., Moreno, K., 2012. Trace element partitioning between majoritic garnet and silicate melt at 10-17 GPa: Implications for deep mantle processes. Lithos 148, 128-141.

Cottrell, E., Walter, M. J., Walker, D., 2009. Metal-silicate partitioning of tungsten at high pressure and temperature: Implications for equilibrium core formation in Earth. Earth Planet. Sci. Lett. 281, 275-287.

Crépisson, C., Morard, G., Bureau, H., Prouteau, G., Morizet, Y., Petitgirard, S., Sanloup, C., 2014. Magmas trapped at depth and the continental lithosphereasthenosphere boundary. Earth Planet. Sci. Lett. 393, 105-112.

Dingwell, D. B., 1998. The glass transition in hydrous granitic melts. Phys. Earth Planet. Int. 107, 1-8.

Draper, D. S., Xirouchakis, D., Agee, C. B., 2003. Trace element partitioning between garnet and chondritic melt from 5 to $9 \mathrm{GPa}$ : implications for the onset of the majorite transition in the martian mantle. Phys. Earth Planet. Int. 139, 149-169.

Drewitt, J. W. E., Jahn, S., Sanloup, C., de Grouchy, C., Garbarino, G., Hennet, L., 2015. Development of chemical and topological structure in aluminosilicate liquids and glasses at high pressure. J. Phys.: Cond. Matt. 27, 105103. 
Drewitt, J. W. E., Sanloup, C., Bytchkov, A., Brassamin, S., Hennet, L., 2013. Structure of $\left(\mathrm{Fe}_{x} \mathrm{Ca}_{1-x} \mathrm{O}\right)_{y}\left(\mathrm{SiO}_{2}\right)_{1-y}$ liquids and glasses from high-energy x-ray diffraction: Implications for the structure of natural basaltic magmas. Phys. Rev. B 87, 224201.

Evans, T. M., O'Neill, H. S. C., Tuff, J., 2008. The influence of melt composition on the partitioning of REEs, Y, Sc, Zr and Al between forsterite and melt in the system CMAS. Geochim. Cosmochim. Acta 72 (23), 5708-5721.

Faber, T., Ziman, J., 1965. A theory of the electrical properties of liquid metals. Philos. Mag. 11, 153-173.

Farges, F., 1996. Does Zr-F 'complexation' occur in magmas? Chem. Geol 127 (4), 253-268.

Fei, Y., Mao, H., 1994. In situ determination of the NiAs phase of FeO at high pressure and temperature. Science 266 (5191), 1678-1680.

Funamori, N., Yamamoto, S., Yagi, T., Kikegawa, T., 2004. Exploratory studies of silicate melt structure at high pressures and temperatures by in situ X-ray diffraction. J. Geophys. Res. 109, B03203.

Gaetani, G., 2004. The influence of melt structure on trace element partitioning near the peridotite solidus. Contrib. Mineral. Petrol. 147 (5), 511-527.

Guillot, B., Sator, N., 2007a. A computer simulation study of natural silicate melts. Part I: low pressure properties. Geochim. Cosmochim. Acta 71, 1249-1265.

Guillot, B., Sator, N., 2007b. A computer simulation study of natural silicate melts. Part II: High pressure properties. Geochim. Cosmochim. Acta 71, 4538-4556.

Guitreau, M., Blichert-Toft, J., Martin, J., Mojszis, S., Albarède, F., 2012. Hafnium isotope evidence from Archean granitic rocks for deep mantle origin of continental crust. Earth Planet. Sci. Lett. 337, 211-213.

Haigis, V., Salanne, M., Simon, S., Wilke, M., Jahn, S., 2013. Molecular dynamics simulations of $\mathrm{Y}$ in silicate melts and implications for trace element partitioning. Chem. Geol. 346 (SI), 14-21.

Hajdu, F., 1972. Revised parameters of the analytic fits for coherent and incoherent scattered x-ray intensities of the first 36 atoms. Acta Cryst., 250-252. 
Hammersley, A., 1996. Fit2D. ESRF publication No ESRF98HA01T.

Hart, S. R., Davis, K. E., 1978. Nickel partitioning between olivine and silicate melt. Earth Planet. Sci. Lett. 40, 203-219.

Holtz, F., Pichavant, M., Barbey, P., Johannes, W., 1992. Effects of H2O on liquidus phase relations in the haplogranite system at 2 and 5 kbar . Am. Mineral. 77 (11-12), $1223-1241$.

Hosemann, R., Bagchi, S. N., 1962. Direct Analysis of Diffraction by Matter. NorthHolland, Amsterdam.

Hubbell, J. H., Veigele, W. J., Briggs, E. A., Brown, R. T., Cromer, D. T., Howerton, R. J., 1975. Atomic form factors, incoherent scattering functions, and photon scattering cross sections. J. Phys. Chem. Ref. Data 4, 471.

Imai, T., Takahashi, E., Suzuki, T., Hirata, T., 2012. Element partitioning between olivine and melt up to 10 GPa: Implications for the effect of pressure. Phys. Earth Planet. Int. 212, 64-75.

Kegler, P., Holzheid, A., Frost, D. J., Rubie, D. C., Dohmen, R., Palme, H., 2008. New $\mathrm{Ni}$ and Co metal-silicate partitioning data and their relevance for an early terrestrial magma ocean. Earth Planet. Sci. Lett. 268, 28-40.

Keppler, H., Rubie, D. C., 1993. Pressure-induced coordination changes of transitionmetal ions in silicate melts. Nature $364,54-56$.

Kohara, S., Akola, J., Morita, H., Suzuya, K., Weber, J. K. R., Wilding, M. C., Benmore, C. J., 2011. Relationship between topological order and glass forming ability in densely packed enstatite and forsterite composition glasses. P. Natl. Acad. Sci. 108, 14780-14785.

Kono, Y., Irifune, T., Higo, Y., Inoue, T., Barnhoorn, A., 2010. P-V-T relation of MgO derived by simultaneous elastic wave velocity and in situ x-ray measurements: A new pressure scale for the mantle transition region. Phys. Earth Planet. Int. 183, 196-211.

Kono, Y., Park, C., Kenney-Benson, C., Shen, G., Wang, Y., 2014. Toward comprehensive studies of liquids at high pressures and high temperatures: Combined structure, elastic wave velocity, and viscosity measurements in the Paris-Edinburgh cell. Phys. Earth Planet. Int. 228, 269-280. 
McIntire, W., 1963. Trace element partitioning coefficients - a review of theory and applications to geology. Geochim. Cosmochim. Acta 27, 1209-1264.

Meade, C., Hemley, R. J., Mao, H. K., 1992. High-pressure x-ray diffraction of $\mathrm{SiO}_{2}$ glass. Phys. Rev. Lett. 69, 1387-1390.

Mysen, B. O., Virgo, D., Harrison, W., Scarfe, C., 1980. Solubility mechanisms of $\mathrm{H}_{2} \mathrm{O}$ in silicate melts at high pressures and temperatures: a Raman spectroscopic study. Am. Miner. 65, 900-914.

Ponader, C., Brown, G., 1989. Rare earth elements in silicate glass/melt systems: I. effects of composition on the coordination environments of La, Gd, and Yb. Geochim. Cosmochim. Acta 53, 2893-2903.

Prowatke, S., Klemme, S., 2005. Effect of melt composition on the partitioning of trace elements between titanite and silicate melts. Geochim. Cosmochim. Acta 69, 695-709.

Prowatke, S., Klemme, S., 2006. Rare earth element partitioning between titanite and silicate melts: Henry's law revisited. Geochim. Cosmochim. Acta 70, 4997-5012.

Ryerson, F., Hess, P., 1978. Implications of liquid-liquid distribution coefficients to mineral-liquid partitioning. Geochim. Cosmochim. Acta 42, 921-932.

Salters, V., Longhi, J., Bizimis, M., 2002. Near mantle solidus trace element partitioning at pressures up to $3.4 \mathrm{GPa} . \mathrm{G}^{3} 3$.

Salters, V. J. M., Longhi, J., 1999. Trace element partitioning during the initial stages of melting beneath mid-ocean ridges. Earth Planet. Sci. Lett. 166, 15-30.

Sanloup, C., JUL 1 2016. Density of magmas at depth. Chem. Geol. 429, 51-59.

Sanloup, C., Drewitt, J. W. E., Konôpková, Z., Dalladay-Simpson, P., Morton, D. M., Rai, N., van Westrenen, W., Morgenroth, W., 2013. Structural change in molten basalt at deep mantle conditions. Nature 503, 104-107.

Sanloup, C., van Westrenen, W., Dasgupta, R., Maynard-Casely, H. E., Perrillat, J.-P., 2011. Compressibility change in iron-rich melt and implications for core formation models. Earth Planet. Sci. Lett. 306, 118-122. 
Sato, T., Funamori, N., 2010. High-pressure structural transformation of $\mathrm{SiO}_{2}$ glass up to 100 GPa. Phys. Rev. B 82, 184102.

Schmidt, M. W., Connolly, J. A. D., Gunther, D., Bogaerts, M., 2006. Element partitioning: The role of melt structure and composition. Nature 312, 1646-1650.

Shannon, R. D., 1976. Revised effective ionic radii and systematic studies of interatomic distances in halides and chalcogenides. Acta Crystallogr., 751-767.

Simon, S., Wilke, M., Chernikov, R., Klemme, S., Hennet, L., 2013. The influence of composition on the local structure around yttrium in quenched silicate melts insights from EXAFS. Chem. Geol. 346, 3-13.

Sun, N., Stixrude, L., de Koker, N., Karki, B. B., 2011. First principles molecular dynamics simulations of diopside $\left(\mathrm{CaMgSi}_{2} \mathrm{O}_{6}\right)$ liquid to high pressure. Geochim. Cosmochim. Acta 75, 3792-3802.

Suzuki, T., Hirata, T., Yokoyama, T. D., Imai, T., Takahashi, E., 2012. Pressure effect on element partitioning between minerals and silicate melt: Melting experiments on basalt up to 20 GPa. Phys. Earth Planet. Int. 208, 59-73.

Uhlig, H., Hoffmann, M. J., Lamparter, P., Steeb, S., 1998. Atomic structure of rare earth Si-Al-O-N glasses. Z. Naturforsch. 53, 259-264.

van Westrenen, W., Allan, N. L., Blundy, J. D., Purton, J. A., Wood, B. J., 2000. Atomistic simulation of trace element incorporation into garnets - comparison with experimental garnet-melt partitioning data. Geochim. Cosmochim. Acta 64, 16291639.

van Westrenen, W., Draper, D. S., 2007. Quantifying garnet-melt trace element partitioning using lattice-strain theory: new crystal-chemical and thermodynamic constraints. Contrib. Mineral. Petrol. 154 (6), 717-730.

van Westrenen, W., Wood, B. J., Blundy, J., 1999. Crystal-chemistry controls on trace element partitioning between garnet and anhydrous silicate melts. Am. Mineral. 84, 838-847.

Vuilleumier, R., Sator, N., Guillot, B., 2009. Computer modeling of natural silicate melts: What can we learn from ab initio simulations. Geochim. Cosmchim. Acta 73, 6313-6339. 
Wang, Y. B., Sakamaki, T., Skinner, L. B., Jing, Z., Yu, T., Kono, Y., Park, C., Shen, G., Rivers, M. L., Sutton, S. R., 2014. Atomistic insight into viscosity and density of silicate melts under pressure. Nature Comm. 5, 3241.

Wood, B., Blundy, J., 1997. A predictive model for rare earth element partitioning between clinopyroxene and anhydrous silicate melt. Contrib. Mineral. Petrol. 129 (23), 166-181.

Wood, B. J., Blundy, J. D., 2013. Trace Element Partitioning : The Influences of Ionic Radius, Cation Charge, Pressure, and Temperature. Vol. 437. JAI-Elsevier Science inc., pp. 421-448.

Yamada, A., Inoue, T., Urakawa, S., Funakoshi, K.-i., Funamori, N., Kikegawa, T., Ohfuji, H., Irifune, T., 2007. In situ X-ray experiment on the structure of hydrous Mg-silicate melt under high pressure and high temperature. Geophys. Res. Lett. $34(10)$.

Yarger, J. L., Smith, K. H., Nieman, R. A., Diefenbacher, J., Wolf, G. H., Poe, B. T., McMillan, P. F., 1995. Al coordination changes in high-pressure aluminosilicate liquids. Science 270, 1964-1967.

Zeidler, A., Drewitt, J. W. E., Salmon, P. S., Barnes, A. C., Crichton, W. A., Klotz, S., Fischer, H. E., Benmore, C. J., Ramos, S., Hannon, A. C., 2009. Establishing the structure of $\mathrm{GeS}_{2}$ at high pressures and temperatures: a combined approach using x-ray and neutron diffraction. J. Phys. Cond. Matt. 21 (47). 